\title{
EFEKTIVITAS SENAM HAMIL TERHADAP KELANCARAN PERSALINAN KALA II PADA IBU INPARTU DI PUSKESMAS BULUPODDO KABUPATEN SINJAI
}

\author{
Marlina Azis ${ }^{1 *}$. Nurfaizah $\mathrm{Alza}^{2}$. Nurhidayat Triananinsi ${ }^{2}$. Andi Yuyun Dian Pertiwi ${ }^{3}$, Mudyawati \\ Kamaruddin $^{4}$ \\ ${ }^{1}$ Program D3 Kebidanan, Universitas Megarezky Makassar \\ ${ }^{2}$ Program Pendidikan Profesi Bidan, Universitas Megarezky Makassar \\ ${ }^{3}$ Program DIV Kebidanan, Universitas Megarezky Makassar \\ ${ }^{4}$ Program Studi Kebidanan, Akademi Kebidanan Tahirah Al Baeti, Bulukumba, Sulawesi Selatan, \\ Indonesia
}

*Corresponding Author: Telp: +6282292537542, E-mail: azismarlina88@ gmail.com

\begin{abstract}
ABSTRAK
Senam hamil yang dilakukan secara teratur selama masa tiga bulan (trimester ketiga) terakhir dapat mengurangi resiko partus lama. Hal ini terjadi karena peningkatan kadar hormon endorphin dalam tubuh sewaktu senam, yang secara alami berfungsi sebagai penahan rasa sakit. Penelitian ini bertujuan untuk mengetahui efektivitas senam hamil terhadap kelancaran persalinan kala II pada ibu inpartu di Puskesmas Bulupoddo Kab. Sinjai. Penelitian ini menggunakan studi analitik dengan menggunakan pendekatan cross sectional. Teknik pengambilan sampel dengan purposive sampling. Responden pada penelitian ini adalah ibu bersalin yang memenuhi persyaratan dengan sebanyak 35 orang. Berdasarkan hasil penelitian tersebut didapatkan hasil dari 35 responden yang diteliti terdapat 91,4\% (32 orang) yang melakukan senam hamil dengan $85,7 \%$ yang mengalami persalinan kala II normal dan sisanya sebanyak $5,7 \%$ yang melakukan senam hamil tapi mengalami persalinan kala II tidak normal. Sedangkan dan 3 orang $(8,6 \%)$ yang tidak melakukan senam hamil dan mengalami persalinan tidak normal. Berdasarkan hasil penelitian di atas menunjukkan $\rho<\alpha$ yang artinya 0,005 lebih kecil dari nilai 0,05 , artinya terdapat hubungan signifikan antara senam hamil dan terjadinya kelancaran persalinan kala II ibu inpartu di Puskesmas Bulupoddo Kabupaten Sinjai. Sebaiknya ibu hamil rutin melakukan senam hamil untuk menjaga kebugaran dan memperlancar proses persalinan demi kesehatan ibu dan janinnya.
\end{abstract}

Kata kunci: Senam Hamil, Kelancaran Persalinan Kala II, Efektifitas

\section{ABSTRACT}

Pregnant exercise done regularly during the last three months (the third trimester) can reduce the risk of prolonged labor. This occurs because of increased levels of the endorphin hormone in the body during gymnastics, which naturally functions as a painkiller. This study aims to determine the effectiveness of pregnancy exercises for the smooth delivery of the second stage of maternity in the Bulupoddo Health Center, Kab. Sinjai. In this study using analytic studies with a cross-sectional approach, and purposive sampling as the sampling technique. Respondents in this study were women who fulfilled the requirements with a total of 35 people. The results obtained are there are 32 people approximately $91.4 \%$ who did pregnancy exercises with $85.7 \%$ experiencing normally childbirth. The remaining $5.7 \%$ experienced an abnormal delivery. Meanwhile, 3 people $(8.6 \%)$ who did not do pregnancy exercises, experienced an abnormal delivery. Based on the results obtained shows the value of $\rho<\alpha$ means 0.005 is smaller than 0.05 in this case there is a significant relationship between pregnancy exercise activities with the smoothness of the second stage of labor in maternity at the Bulupoddo Health Center in Sinjai Regency. We recommend that pregnant women routinely do pregnancy exercises to maintain fitness and facilitate the delivery process for the health of the mother and fetus.

Keywords: Pregnancy Exercise, Smooth Second Stage of Labor, Effectiveness

\section{PENDAHULUAN}

Persalinan merupakan proses keluarnya janin, plasenta dan membran dari dalam rahim melalui jalan lahir. Proses ini berawal dari pembukaan dan dilatasi serviks sebagai akibat kontraksi uterus dengan frekuensi, durasi dan kekuatan yang teratur. Mula-mula kekuatan yang muncul kecil, kemudian terus meningkat sampai pada puncaknya pembukaan serviks lengkap sehingga siap untuk pengeluaran janin dari rahim ibu (Rohani, 2014).

Penyebab langsung kematian ibu adalah faktor yang berhubungan dengan komplikasi kehamilan, persalinan dan nifas seperti perdarahan, 
preeklampsia atau eklampsia, infeksi, partus lama dan abortus. Penyebab tidak langsung kematian ibu adalah faktor-faktor yang memperberat keadaan ibu hamil, maupun yang mempersulit proses penanganan kedaruratan kehamilan, persalinan dan nifas.

Persalinan dibedakan menjadi dua berdasarkan cara persalinannya yaitu partus normal dan partus abnormal. Partus normal atau partus spontan adalah proses lahirnya bayi dengan tenaga ibu sendiri, tanpa bantuan alat-alat serta tidak melukai ibu dan bayi yang umumnya berlangsung kurang 24 jam. Sedangkan partus abnormal adalah persalinan dengan bantuan alat-alat atau melalui dinding-dinding perut dengan operasi sectio caesarea. Sampai saat ini yang dapat dilakukan manipulasi/dikendalikan adalah masalah tenaga/power yaitu ditingkatkan dengan senam hamil (Stoppard, 2013).

Dalam proses persalinan memerlukan persiapan fisik maupun mental dari ibu supaya memperoleh persalinan yang aman dan lancar. Berbagai cara dilakukan demi terlaksananya persalinan yang aman dan lancar diantaranya yang dilakukan sejak kehamilan diantaranya melakukan senam hamil. Ini jelas merupakan masalah yang sangat serius yang harus diperhatikan oleh tenaga kesehatan untuk memperbaiki tingkat keseriusan dari masalah tersebut. Salah satu program kelancaran persalinan yaitu senam hamil.

Senam hamil merupakan suatu program latihan bagi ibu hamil sehat untuk mempersiapkan kondisi fisik ibu dengan menjaga kondisi otot-otot dan persendian yang berperan dalam proses persalinan, serta mempersiapkan kondisi psikis ibu terutama menumbuhkan kepercayaan diri dalam menghadapi persalinan. Senam hamil memberikan manfaat terhadap komponen biomotorik otot yang dilatih. Olahraga atau senam yang teratur selama kehamilan dihubungkan dengan melahirkan tepat pada waktunya. Manfaat lain senam hamil langsung atau berperan menurunkan angka kesakitan dan kematian ibu dan bayi yang lahir (Thompson, 2013).

Salah satu program kelancaran persalinan yaitu senam hamil merupakan suatu program latihan bagi ibu hamil sehat, untuk mempersiapkan kondisi fisik ibu dengan menjaga kondisi otot-otot dan persendian yang berperan dalam proses persalinan serta mempersiapkan psikis ibu terutama menumbuhkan kepercayaan diri dalam menghadapi persalinan.

Latihan senam hamil yang dilakukan secara teratur dapat menuntun ibu hamil ke arah persalinan yang fisiologis selama tidak ada keadaan patologis yang menyertai kehamilan. Ibu hamil yang melakukan senam hamil secara teratur selama kehamilannya dilaporkan dapat memberikan keuntungan pada saat persalinan yaitu pada kala aktif (kala II) menjadi lebih pendek, mencegah terjadinya letak sungsang dan mengurangi terjadinya kejadian sectio caesaria. Jika tidak melakukan senam hamil dapat mengakibatkan perasaan tegang saat kehamilan atau persalinan, sistem tubuh akan terhalang dan mempengaruhi persediaan oksigen untuk otot-otot maupun organ tubuh dan bayi. Perasaan tegang saat persalinan juga dapat membuat proses persalinan terhambat (Penny, 2013).

Menurut data World Health Organization (WHO) memperkirakan sekitar 15\% dari seluruh wanita hamil akan berkembang menjadi komplikasi yang berkaitan dengan kehamilannya serta mengancam jiwanya. Pada sebuah penelitian atas 876 pasien hamil di New York yang melakukan olahraga, persalinan lebih mudah dikalangan yang melakukan latihan secara teratur dibandingkan dengan yang hanya latihan sedikit atau yang tidak melakukan latihan sama sekali dan juga didapatkan penurunan resiko persalinan terlalu lama.

Data ibu hamil di Indonesia adalah 5.082.537 orang. Dari seluruh ibu hamil yang mengalami komplikasi kehamilan dan persalinan $11 \%$ diantaranya disebabkan oleh Partus lama (DEPKES, 2017).

Ibu hamil yang melakukan kegiatan senam cukup sering dan teratur selama masa tiga bulan (trimester) terakhir, rasa sakit yang dirasakan pada masa persalinan akan berkurang bila dibandingkan dengan persalinan ibu yang tidak melakukan kegiatan senam hamil. Hal ini terjadi karena peningkatan kadar hormon endorphin dalam tubuh sewaktu senam, yang secara alami berfungsi sebagai penahan rasa sakit (Hanton, 2013).

Hasil penelitian Nurtang (2016) menyimpulkan ada hubungan signifikan antara senam hamil dengan proses persalinan kala II. Dengan proses persalinan kala II, ibu-ibu yang rutin melakukan senam hamil menurunkan insiden partus lama, mal presentasi janin, inersia uteri (stimulasi persalinan) dan partus tindakan.

Pada beberapa penelitian didapatkan bahwa berat bayi yang lahir dari wanita hamil yang melakukan senam/olahraga selama kehamilannya lebih berat dibandingkan yang tidak melakukan olahraga. Hal ini disebabkan olahraga akan meningkatkan aliran darah ke uterus yang merupakan jalan terpenting bagi suplai nutrisi dan metabolisme janin, terdapat hubungan positif antara berat plasenta dan berat badan lahir (Hendarmin, 2013).

Data ibu hamil di Sulawesi Selatan sekitar 187.141 orang. Adapun hasil insiden yang tidak mengikuti senam hamil adalah $(95,1 \%)$ dan pada kasus yang mengikuti senam hamil adalah $(1,9 \%)$ (RISKESDAS, 2018).

Berdasarkan pengambilan data awal yang telah dilakukan di Puskesmas Bulupoddo Kab. Sinjai tahun 2018, pada tahun 2016 jumlah ibu yang mengikuti senam hamil sebanyak 30 orang $(27 \%)$ dari 113 ibu primigravida. Pada tahun 2017 jumlah ibu yang mengikuti senam hamil sebanyak 33 orang $(28 \%)$ dari 117 ibu primigravida. Pada bulan Januari-November 2018 jumlah ibu yang mengikuti senam hamil sebanyak 25 orang (23\%) 
dari 107 ibu primigravida. Sedangkan pada tahun 2016 jumlah ibu yang mengalami partus lama sebanyak 17 orang (15\%) dari 113 ibu primigravida. Pada tahun 2017 jumlah ibu yang mengalami partus lama sebanyak 15 orang (13\%) dari 117 ibu primigravida. Pada bulan JanuariNovember 2018 jumlah ibu yang mengalami partus lama sebanyak 11 orang $(10 \%)$ dari $107 \mathrm{ibu}$ primigravida.

Berdasarkan uraian diatas, peneliti tertarik untuk meneliti lebih dalam tentang "Efektivitas Senam Hamil Terhadap Kelancaran Persalinan Kala II Pada Ibu Inpartu di Puskesmas Bulupoddo Kabupaten Sinjai Tahun 2019".

\section{METODOLOGI}

Penelitian ini merupakan studi Analitik dengan menggunakan pendekatan cross sectional. Cross sectional adalah sebuah penelitian yang dilakukan dalam sekali waktu saja, tidak ada pengulangan dalam pemgambilan data. Populasi dalam penelitian ini adalah 113 ibu hamil primigravida yang melahirkan di Puskesmas Bulupoddo Kab.Sinjai pada tanggal 18 Februari 26 Agustus tahun 2019. Kriteria Inklusi dalam penelitian ini adalah umur kehamilan $\geq 6$ bulan ( 24 minggu) hingga menjelang persalinan, ibu hamil primigravida yang melahirkan di Puskesmas Bulupoddo tahun 2019, bersedia menjadi responden, persalinan normal, tidak ada komplikasi, kehamilan tunggal. Kriteria ekslusi dalam penelitian ini adalah Umur kehamilan $<6$ bulan (24 minggu), Ibu hamil multigravida yang melahirkan di PuskesmasBulupoddo tahun 2019, tidak bersedia menjadi responden, Persalinan abnormal, ada komplikasi, kehamilan gemelli. Penelitian ini menggunakan metode penelitian system Purposive Sampling.

Data primer adalah Pengumpulan data dilakukan dengan menggunakan lembar observasi dengan melakukan pengamatan langsung kepada ibu hamil primigravida yang melahirkan di Puskesmas Bulupoddo Kabupaten Sinjai yang dikumpulkan selama penelitian pada tanggal 18 Februari - 26 Agustus tahun 2019. Data Sekunder yaitu Pengumpulan data dilakukan dengan melihat jumlah ibu hamil primigravida yang melahirkan di Puskesmas Bulupoddo Kabupaten Sinjai pada tanggal 18 Februari - 26 Agustus tahun 2019.

\section{HASIL PENILITIAN}

\section{AnalisisUnivariat}

Analisis univariat dilakukan untuk menilai distribusi frekuensi variabel yang relevan dengan tujuan penelitian sebelum dianalisis lebih lanjut. Adapun variabel yang dimaksud dalam analisis univariat adalah sebagai berikut:

a. DistribusiFrekuensidanPresentaseBerdasarkan SenamHamil

\begin{tabular}{|c|c|c|}
\hline SenamHamil & Frekuensi & $\begin{array}{c}\text { Persentase } \\
(\mathbf{\%})\end{array}$ \\
\hline Ya & 32 & 91,4 \\
\hline Tidak & 3 & 8,6 \\
\hline Total & $\mathbf{3 5}$ & $\mathbf{1 0 0}$ \\
\hline
\end{tabular}

Sumber: Data Primer, 2019

Berdasarkan tabel menunjukkan bahwa dari 35 responden, terdapat 32 orang $(91,4 \%)$ yang melakukan senam hamil secara teratur dan terdapat 3 orang $(8,6 \%)$ yang tidak melakukan senam hamil secara teratur.

b. DistribusiFrekuensidanPresentaseBerdasarkan KelancaranPersalinan Kala II

\begin{tabular}{|c|c|c|}
\hline $\begin{array}{c}\text { Kelancaran } \\
\text { Persalinan }\end{array}$ & Frekuensi & $\begin{array}{c}\text { Persentase } \\
(\mathbf{\%})\end{array}$ \\
\hline Normal & 33 & 94,3 \\
\hline $\begin{array}{c}\text { Tidak } \\
\text { Normal }\end{array}$ & 2 & 5,7 \\
\hline Total & $\mathbf{3 5}$ & $\mathbf{1 0 0}$ \\
\hline
\end{tabular}

Sumber: Data Primer, 2019

Berdasarkan tabel 4.7 menunjukkan bahwa dari 35 responden, terdapat 33 orang $(94,3 \%)$ yang mengalami kelancaran persalinan kala II dan terdapat 2 orang $(5,7 \%)$ yang tidak mengalami kelancaran persalinan kala II.

\section{Analisis Bivariat}

Analisis bivariat dilakukan untuk mengetahui hubungan variabel independen dan dependen. Uji statistik yang digunakan adalah Fisher's Exact Test dengan tingkat kemaknaan $\alpha=0,05$. Hubungan variabel independen terhadap dependen dijabarkan sebagai berikut:

\begin{tabular}{|c|c|c|c|c|c|c|c|}
\hline \multirow{3}{*}{$\begin{array}{l}\text { Senam } \\
\text { Hamil }\end{array}$} & \multicolumn{4}{|c|}{$\begin{array}{c}\text { KelancaranPersalin } \\
\text { an Kala II }\end{array}$} & \multicolumn{2}{|c|}{ Total } & \multirow{3}{*}{$\begin{array}{c}\text { P. } \\
\text { Valu } \\
\mathrm{e} \\
\alpha= \\
0,05\end{array}$} \\
\hline & \multicolumn{2}{|c|}{ Normal } & \multicolumn{2}{|c|}{\begin{tabular}{|c|} 
Tidak \\
Normal
\end{tabular}} & $\mathbf{N}$ & $\%$ & \\
\hline & $\mathbf{N}$ & $\%$ & $\mathbf{N}$ & $\%$ & & & \\
\hline Ya & 32 & 100 & 0 & 0 & 32 & 100 & $\mathrm{P}=$ \\
\hline Tidak & 1 & 33,3 & 2 & 66,7 & 3 & 100 & 0,00 \\
\hline Total & 33 & 94,3 & 2 & 5,7 & 35 & 100 & 5 \\
\hline
\end{tabular}

Berdasarkan tabel 4.8 menunjukkan dari 35 responden yang melakukan senam hamil secara teratur terdapat 32 orang $(100 \%)$ yang mengalami proses persalinan kala II normal sementara terdapat 2 orang $(66,7 \%)$ yang tidak melakukan senam hamil secara teratur dan mengalami proses persalinan kala II tidak normal dan terdapat 1 orang $(33,3 \%)$ yang tidak melakukan senam hamil secara teratur tetapi mengalami persalinan kala II normal.

Berdasarkan hasil uji Fisher's Exact Test menunjukkan nilain $\mathrm{P}=0,005$ dengan taraf signifikan $\alpha=0,05$. Oleh karena nilai $\mathrm{P}=<0,05$ 
maka dapat disimpulkan bahwa Ho ditolak dan Ha diterima berarti ada hubungan senam hamil terhadap kelancaran persalinan kala II.

\section{PEMBAHASAN}

Senam hamil bermanfaat untuk memperkuat serta mempertahankan elastisitas otot dinding perut, ligamen-ligamen dan otot dasar panggul yang semuanya berhubungan dengan proses persalinan. Dengan latihan yang teratur, minimal 1 kali dalam seminggu dengan lama latihan 30 menit, maka hasil yang didapatkan akan maksimal sehingga proses persalinan merupakan bagian yang menyenangkan bagi ibu.

Hasil penelitian menunjukkan dari menunjukkan dari 35 responden yang melakukan senam hamil secara teratur terdapat 32 orang (100\%) yang mengalami proses persalinan kala II normal sementara terdapat 2 orang $(66,7 \%)$ yang tidak melakukan senam hamil secara teratur dan mengalami proses persalinan kala II tidak normal dan terdapat 1 orang $(33,3 \%)$ yang tidak melakukan senam hamil secara teratur tetapi mengalami persalinan kala II normal. Hasil uji chi square diperoleh nilai $\mathrm{P}$ value $=0,005(\alpha>0,05)$ karena Ho ditolak dan Ha diterima maka dapat disimpulkan bahwa senam hamil memiliki hubungan dengan kelancaran persalinan kala II pada ibu inpartu.

Penelitian ini sejalan dengan penelitian yang dilakukan Sri Wahyuni, 2013. Efektivitas senam hamil terhadap kelancaran persalinan di Puskesmas Batua Kota Makassar. Dari hasil uji Fisher's Exact Test menunjukkan nilai $\mathrm{P}=0,02<0,05$ karena $\mathrm{Ho}$ ditolak dan Ha diterima yang berarti ada hubungan antara senam hamil dengan kelancaran proses persalinan.

Penelitian ini sejalan juga dengan penelitian yang dilakukan Nurtang, tahun 2016. Hubungan senam hamil terhadap kelancaran proses persalinan di RSIA Sitti Khadijah I Kota Makassar. Dari hasil uji Fisher's Exact Test menunjukkan nilai $\mathrm{P}=$ $0,002<0,05$ karena Ho ditolak dan Ha diterima yang berarti ada hubungan antara senam hamil dengan kelancaran proses persalinan.

Senam hamil adalah program kebugaran yang diperuntukkan bagi ibu hamil (Mufdillah, 2013). Senam hamil merupakan sebuah program fisik yang sangat penting bagi calon ibu untuk mempersiapkan persalinannya.

Senam hamil pada dasarnya adalah bentuk latihan untuk memperkuat dan juga mempertahankan kelenturan dari dinding perut, otot-otot dan dasar panggul ibu hamil.

Senam hamil diperlukan untuk memperoleh ketenangan dan relaksasi serta menurunkan ketegangan (Mochtar, 2012). Relaksasi merupakan latihan pernapasan dan pemusatan perhatian yang bermanfaat menenangkan pikiran dan tubuh, membantu ibu menyimpan energi untuk ibu agar siap menghadapi persalinan. Dampak ibu yang tidak melakukan senam hamil lebih rentan mengalami ketegangan jiwa dan fisik yang menyebabkan otot dan persendian kaku. Manfaat senam hamil rutin tidak hanya untuk kenyamanan ibu selama kehamilan, namum juga memberikan banyak manfaat dalam persalinan. Manfaat senam hamil selama kala I dapat menurunkan inseden partus lama, mengurangi rasa sakit dan menurunkan kecemasan ibu dalam menghadapi persalinan karena latihan senam hamil yang rutin dapat mempengaruhi elastisitas otot dan ligament yang ada dipanggul, mengatur teknik pernapasan.

Manfaat senam hamil selama kala II dapat membantu ibu menjalani persalinan yang normal dengan lama persalinan yang normal, karena pada senam hamil ibu telah dibimbing cara mengedan dan mengatrur napas, mengatur kontraksi dan relaksasi serta melatih kelenturan otot-otot dinding perut dan dasar panggul sehingga memudahkan persalinan. Selama persalinan kala III dan kala IV latihan senam hamil sangat bermanfaat dalam mencegah perdarahan berlebihan, karena dapat meningkatkan kemampuan mengkoordinasikan kekuatan kontraksi otot rahim. Banyak gerakangerakan senam hamil yang berpengaruh terhadap kesehatan, kenyamanan ibu selama kehamilan dan juga kelancaran persalina, diantaranya gerakan merangkak dan berjongkok yang berfungsi untuk membantu bagian terberat janin dan terhindar dari bayi sungsang serta gerakan berbaring yang berfungsi untuk membantu ibu posisi melahirkan yang baik.

Persalinan adalah proses membuka dan menipisnya serviks dan janin turun kedalam jalan lahir (Wiknjosastro, 2013). Persalinan dan kelahiran normal adalah proses pengeluaran janin yang terjadi pada kehamilan cukup bulan (37-42 minggu), lahir spontan dengan presentasi belakang kepala, tanpa komplikasi baik ibu maupun janin (Hidayat, 2013). Tahapan persalinan terdiri dari IV kala

yaitu kala I atau kala pembukaan dimulai dari adanya his yang adekuat sampai pembukaan lengkap. Kala I dibagi dalam 2 fase: fase laten dan fase aktif. Kala II atau pengeluaran dimulai dari pembukaan lengkap sampai lahirnya bayi. Proses ini berlangsung 2 jam pada primi dan 1 jam pada multi. Kala III atau kala uri dimulai segera setelah bayi lahir sampai lahirnya plasenta yang berlangsung tidak lebih dari 30 menit. Kala IV atau kala pengawasan dimulai dari saat lahirnya plasenta sampai 2 jam pertama post partum (Hidayat, 2013).

Peneliti berasumsi bahwa pada 2 responden yang tidak melakukan senam hamil secara teratur dan mengalami proses persalinan kala II tidak normal hal ini disebabkan oleh faktor $\mathrm{HB}$ ibu. Dimana dari kedua responden yang proses persalinan kala II tidak normal semuanya mempunyai HB 9-10 gr\%, dimana kita ketahui HB 9-10 gr\% beresiko anemia yang mengakibatkan penurunan transportasi oksigen dari paru ke jaringan perifer selama kehamilan. Anemia biasaya disebabkan oleh karena defisiensi besi sekunder 
terhadap kehilangan darah sebelumnya atau masukan zat besi yang tidak adekuat.

Sedangkan ada 1 responden yang tidak melakukan senam hamil secara teratur akan tetapi mengalami proses persalinan kala II normal hal ini disebabkan oleh faktor BBL bayi. Dimana kita ketahui BBL bayi 2700 gr merupakan BBL bayi normal dan dengan kontraksi serta tenaga yang adekuat sehingga menyebabkan proses persalinan kala II normal.

\section{KESIMPULAN}

Dari hasil penelitian yang dilakukan pada tanggal 18 Februari- 26 Agustus tahun 2019 terdapat 35 responden di Puskesmas Bulupoddo Kab.Sinjai tahun 2019, maka peneliti dapat menyimpulkan bahwa:

1. Dari 35 responden, yang melakukan senam hamil sebanyak 32 orang $(91,4 \%)$ dan yang tidak melakukan senam hamil sebanyak 3 orang $(8,6 \%)$ di Puskesmas Bulupoddo Kab.Sinjai tahun 2019.

2. Dari 35 responden, yang mengalami proses persalinan

3. kala II normal sebanyak 33 responden $(94,3 \%)$ dan yang mengalami proses persalinan kala II tidak normal sebanyak 2 responden $(5,7 \%)$ di Puskesmas Bulupoddo Kab.Sinjai tahun 2019.

4. Ada hubungan yang signifikan antara senam hamil dengan kelancaran persalinan kala II. Dengan demikian, dengan teratur melakukan kegiatan senam hamil akan sangat berpengaruh untuk kelancaran persalinan kala II normal.

\section{DAFTAR PUSTAKA}

1. Anik. (2013). Mempersiapkan Persalinan Sehat. Jakarta: Puspa Swara.

2. Aulia. (2014).Hamil Sehat Beragam Olahraga Ibu Hamil. Jogjakarta: Buku Biru.

3. Arikunto. (2013). Prosedur Penelitian Suatu Pendekatan Praktik. Jakarta: Rineka Cipta.

4. Bandiyah, Brayshaw, dkk. (2013). Senam Hamil \& Nifas Pedoman Praktis Bidan. Jakarta : EGC

5. Departemen Kesehatan RI. (2013). Asuhan Persalinan Revisi. Jakarta : JNPK-KR

6. Hanton, T.W. (2013). Panduan Senam Kebugaran Untuk Wanita Hamil. Jakarta : Raya Gravindo Persada.

7. Hidayat, Asri, dkk. (2013). Asuhan Kebidanan Persalinan. Jogjakarta: Nuha Medika

8. Indah, Kiki, dkk. (2013). Hubungan Antara Pengetahuan Ibu Hamil Tentang Senam
Hamil Dengan Minat Melakukan Senam Hamil Di RB RIEN'S Kediri Tahun 2013.Jurnal Kesehatan Masyarakat.

9. Kuswanti, I. (2014). Asuhan Kehamilan. Yogyakarta: Pustaka Pelajar

10. Locana, Roosytasari. (2013). Hubungan Antara Senam Hamil Dengan Proses Persalinan Normal Di Rumah Bersalin As Syifa' Ul Ummah Grobogan Tahun 2013.Jurnal Kesehatan Masyarakat.

11. Muhaimah, Nanik, dkk. (2013). Panduan Lengkap Senam Sehat Khusus Ibu Hamil. Yogyakarta: Power Books.

12. Mufdillah. (2013). Panduan Asuhan Kebidanan Ibu Hamil. Jogjakarta: NuhaMedika.

13. Notoatmodjo. (2013). Metode Penelitian Kesehatan. Jakarta: Rineka Cipta.

14. Penny, Ruth, dkk. (2013). Buku Saku Persalinan. Jakarta: EGC.

15. Prawirohardjo, S. (2013).Ilmu Kebidanan. Jakarta: PT. Bina Pustaka

16. Rohani, Saswita, dkk. (2014). AsuhanKebidananPadaMasaPersalinan. Jakarta: SalembaMedika.

17. Saifuddin, AB. (2013). BukuAcuan Pelayanan Kesehatan Maternal dan Neonatal. Jakarta: YBPSP.

18. Saryono, dkk. (2013). Metodologi Penelitian Kualitatif Dalam Bidang Kesehatan. Jogjakarta: Nuha Medika.

19. Sugiyono. (2013). Metode Penelitian Kuantitatif Kualitatif dan R\&D. Jakarta: Alfabeta.

20. Wiknjosastro.(2013). Ilmu Kebidanan. Jakarta: Yayasan Bina Pustaka.

21. Yusnia.(2015). Hubungan Senam Hamil Dengan Lama Proses Persalinan Kala II Pada Ibu Primigravida Di RSKIA Sadewa Yogyakarta Tahun 2013.Jurnal Kesehatan Masyarakat 